\title{
Carotid Body Tumour: The Second Case Series from Baghdad, Iraq
}

\author{
Waleed M. Hussen'1, Abdulsalam Y. Taha ${ }^{2 *}$, Diar S. Hama-Kareem ${ }^{3}$ \\ ${ }^{1}$ Department of Cardiothoracic and Vascular Surgery, College of Medicine, University of Baghdad and Baghdad \\ Medical City Teaching Hospital, Baghdad, Iraq \\ ${ }^{2}$ Department of Cardiothoracic and Vascular Surgery, School of Medicine, Faculty of Medical Sciences, \\ University of Sulaimaniyah and Sulaimaniyah Teaching Hospital, Sulaimaniyah, Iraq \\ ${ }^{3}$ Ibn Al-Betar Center for Cardiac Surgery, Baghdad, Iraq \\ Email: salamyt 1963@hotmail.com
}

Received 27 February 2015; accepted 15 March 2015; published 19 March 2015

Copyright (C) 2015 by authors and Scientific Research Publishing Inc.

This work is licensed under the Creative Commons Attribution International License (CC BY).

http://creativecommons.org/licenses/by/4.0/

(c) (i) Open Access

\section{Abstract}

Background: Carotid body tumour (CBT) is a rare neoplasm, yet it is the commonest head and neck paraganglioma. In Iraq, relevant literature is sparse. Herein, we present our second case series. Methodology: Patients with CBTs that were operated upon in the Department of Thoracic and Vascular Surgery, Baghdad Medical City from 2010 to 2014 were enrolled. History and examination were followed by a workup of duplex ultrasonography, CT scan, magnetic resonance imaging, CT or conventional carotid angiography. Surgical exploration via a standard anterolateral cervical incision and subadventitial dissection was used to resect the tumours with preservation of carotid arteries. Intra-luminal carotid shunts and vein grafts were prepared to be used if necessary. Results: There were 5 males and 2 females aging 17 - 46 with a mean of $32.9 \pm 9.8$ year. All patients had slowly growing painless pulsatile swelling below mandiblular angle for long durations (1 - 25 years) and a positive Fontaine's sign. All tumours were benign, unilateral (right $n=4$, left $n=3$ ) and ranging in size from $3 \times 3 \mathrm{~cm}$ to $6.4 \times 3.2 \mathrm{~cm}$. Beside US neck exam, carotid angiography was done in 5 patients. According to Shamblin classification, 4 were class II, 2 class I and 1 class III. All tumours were successfully resected with preservation of ICA. However, the ECA was safely ligated twice due to severe involvement. Tongue deviation occurred once $(14.3 \%)$ but no patient died and none had stroke or recurrence. Conclusions: Our results of surgery for CBT compare very well with the international standards.

\section{Keywords}

Carotid Body Tumour, Paraganglioma, Chemodectoma, Stroke, Cranial Nerve Deficits

\footnotetext{
${ }^{*}$ Corresponding author.
} 


\section{Introduction}

The carotid body (CB), described for the first time by Albrecht Von Haller in 1743 [1] is a small structure $12 \mathrm{mg}$ in weight [2] located in the adventitia of carotid bifurcation serving as a chemoreceptor [2]. It has both ectodermic and mesoderm tissue elements and consists of 2 types of glomus cells: type I (chief or paraganglion cells) and type II (sustantecular cells). The CB receives its blood supply mainly from the external carotid artery (ECA) and has afferent innervations via the glossopharyngeal nerve [2]. A rare highly vascular mostly benign tumour may arise from the CB paraganglia previously known as chemodectoma or CB paraganglioma [3]. As the paraganglia are widely distributed in the body (in association with the sympathetic and parasympathetic chains from the skull base to pelvic floor); paragangliomas may arise in different locations such as the abdomen, retroperitoneum, mediastinum, head and neck and best named by their location [4]. Carotid body tumour is the commonest head and neck paraganglioma [1]. The exact etiology of CBT is unknown, although its higher incidence among people living at high altitudes or those with chronic obstructive pulmonary disease suggests a role of chronic hypoxia. The tumour mostly occurs in sporadic form while minority of patients had a familial type which is thought to be related to genetic factors. The tumour is usually non-functional but occasionally tumours capable of catecholamine secretion are diagnosed with symptoms similar to pheochromocytoma such as hypertension and tachycardia [1] [3]. Carotid arteriography used to be the gold standard for diagnosis [5], although Duplex US scanning and magnetic resonance arteriography (MRA) are favored by many authors nowadays [6]. Carotid BT has a characteristic histopathological appearance [1]-[3]. It represents a surgical challenge due to its location, high vascularity and potential morbidity and mortality [1] [4] [5]. Surgery is the standard therapy as it provides an immediate and complete removal of the tumour [1] [7]-[9]. However, the morbidity of cranial nerve injuries and stroke associated with surgery is significant [10]. On the other hand, the indolent and very slow growth rate of CBT and the fact that most of them are benign and rarely cause death by themselves encourage some authors to adapt the conservative or the so-called (wait and scan) policy [9]. A third group of workers recommend radiotherapy as a primary mode of management of CBTs to achieve a tumour growth control while avoiding the potential morbidity of surgical intervention [9].

In Iraq, little has been published about this uncommon disease; one paper [7], one $\mathrm{PhD}$ thesis [11] and 2 videos [12] [13] posted on the net demonstrating surgical removal of 2 such tumours. In 2008, Hussen, W. M. [7] described 8 patients in 12-year period (1994-2005) and this is his second case series from the same institute. We aim to present our current management of this uncommon yet serious disease in view of the relevant literature.

\section{Patients and Methods}

Patients with CBTs that were operated upon in the Department of Thoracic and Vascular Surgery, Baghdad Medical City Teaching Hospital over a 4-year period (2010-2014) were enrolled in this prospective study. Detailed history taking and thorough physical examination particularly of the region of the neck were performed. Any cranial nerve involvement was recorded when present. Relevant investigations were ordered such as Duplex US scanning, MRI, MRA, and carotid arteriography (conventional or CT angiography). Preoperative preparation included a thorough medical checkup, fitness for general anaesthesia, blood preparation and written high risk consent was signed by each patient after explaining the possible morbidity and mortality. Due to the nonavailability of indwelling Javid carotid shunt, an alternative shunt (Scribner's shunt of hemodialysis) was prepared.

\section{Surgical Technique}

"The patient is positioned supine with the neck rotated to the opposite side. Since the need for carotid resection cannot always be predicted, one leg is prepared in case the saphenous vein should be required. The carotid artery is exposed through a standard anterolateral cervical incision along the anterior border of the sternocleidomastoid muscle. Control of the common, internal and external carotid arteries is obtained and hypoglossal and vagus nerves are identified. Using the bipolar diathermy, a capsular-adventitial or sub-adventitial (white line) dissection plane is established at the inferior margin of the tumour at bifurcation and extended cephalad onto the internal and external carotid arteries. Branches of external carotid artery may require division to facilitate the dissection (Figure 1). This technique is usually adequate for excision of Shamblin Class I and II tumours" [1] (Figures 2(a)-(c)). "Shamblin Class III tumours are often managed by resection of the involved portion of the 


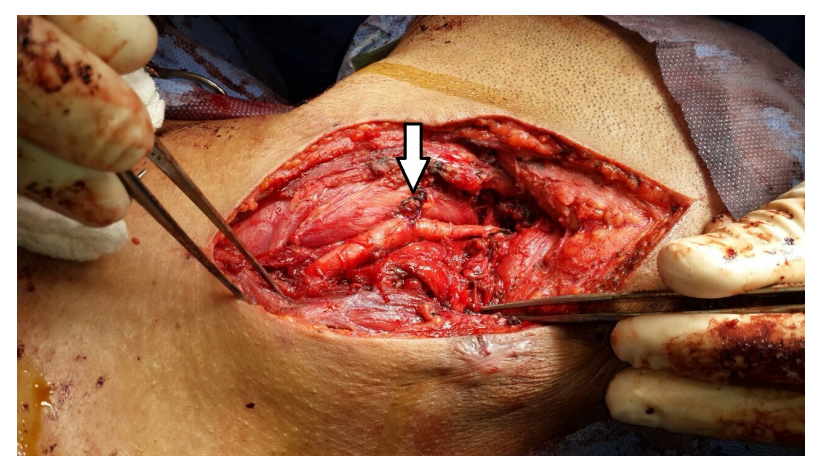

Figure 1. Resection of CBT with ligation of ECA.

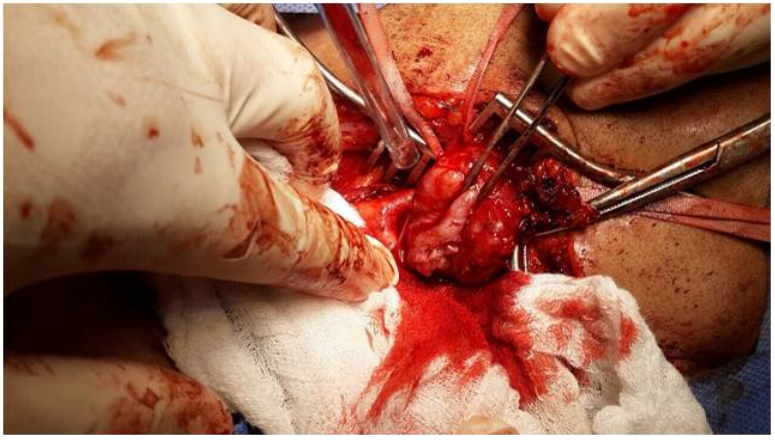

(a)

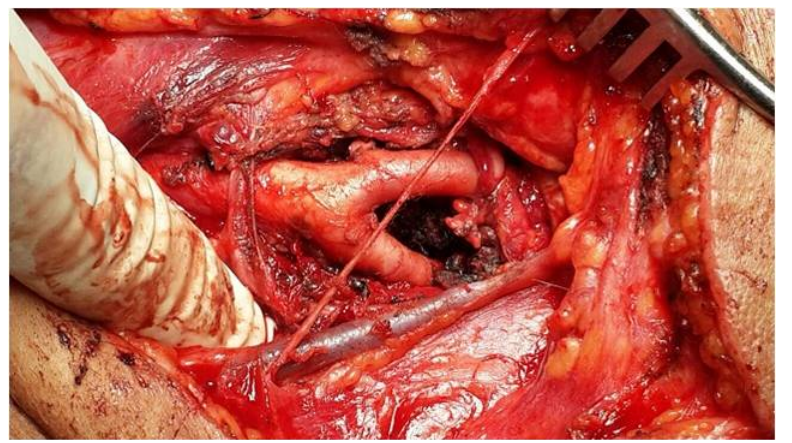

(b)

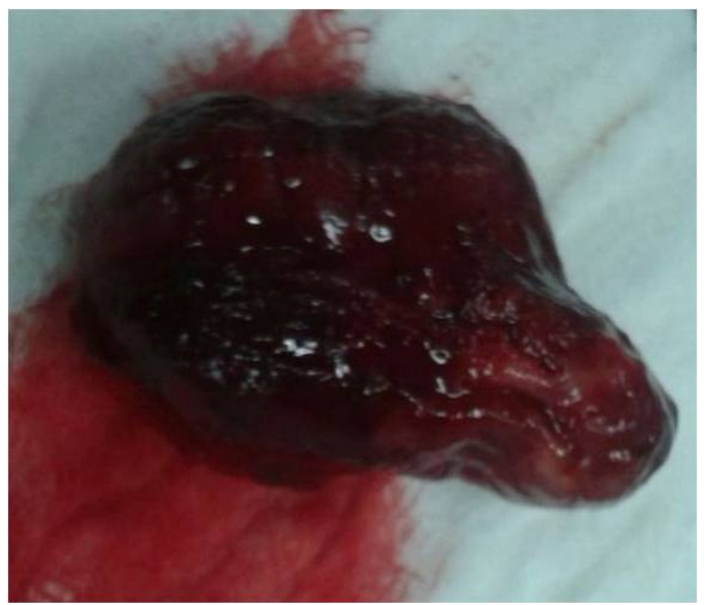

(c)

Figure 2. (a) Shamblin Class II CBT is being removed by subadventitial dissection; (b) Removal of CBT has been completed; (c) Specimen of CBT.

artery and replacement with a saphenous interposition vein graft” [1]. Postoperatively, the patients were evaluated with regard to any evidences of cranial nerve injury. If the postoperative period was uneventful, the patients were discharged home once the condition of the patient was stable. Late outcome was assessed through frequent follow-up visits to the consultation clinic. Statistical analysis was performed using z-test for 2 population proportions and T-test for 2 dependent means.

\section{Results}

Seven patients ( 5 males and 2 females). The male to female ratio was 2.5:1. The youngest was a girl of 17 and the oldest was a man of 46 . The mean age was $32.9 \pm 9.8$ year. 
Table 1 showed the age and sex distribution. The peak was in the $4^{\text {th }}$ decade $(n=4,57.1 \%)$.

The patients lived in the middle and south of Iraq except one patient from Kirkuk in the north. The 2 ladies were a housewife and a student whereas men were (workers $n=3$, soldier $n=1$ and a civil servant $n=1$ ). The demographic and clinical features are shown in Table 2.

There were 5 males and 2 females. All patients had slowly growing painless pulsatile swelling below the angle of the mandible present for long durations ( 1 to 25 years) and a positive Fontainè s sign. All tumours were unilateral ( 4 on the right side and 3 on the left side). There was one patient with hypertension, one with palpable cervical lymph nodes and one with prior history of incisional biopsy (Figure 3) but none had a family history of CBT. Ultrasound neck examination with Doppler of carotid arteries was done in all patients. Carotid angiography was done in 5 patients (Conventional carotid angiography $n=2$ and CT angiography $n=3$ ). Contrast-enhanced CT scan of the neck was done twice. All tumours were benign ranging in size from $3 \times 3 \mathrm{~cm}$ to $6.4 \times 3.2$ $\mathrm{cm}$. According to Shamblin classification, the majority was in class II $(n=4)$ followed by class I $(n=2)$ and one in class III. In all cases, the tumours were successfully resected with preservation of ICA. However, the ECA was ligated twice without bad sequels (in both cases, the ECA was severely involved by the tumour; therefore it was ligated and the tumours were completely excised. The tumours were class II and III and the largest in the series). Lymph nodes were removed in 2 cases and were not malignant. Malignancy was excluded on the basis of absence of regional lymph node involvement and distant metastases. The only postoperative neurological deficit was an ipsilateral tongue deviation that persisted for 1 year in a lady of 35 with Shamblin class II rightsided tumour. No patient died and none has developed a postoperative stroke or recurrence of the tumour during the follow-up period. Table 3 clearly shows that Shamblin class III significantly influenced the occurrence of early neurological deficits $(\mathrm{p}<0.05)$.

Table 1. Age and sex distribution.

\begin{tabular}{cccc}
\hline Age (year) & Male, $\mathrm{n}(\%)$ & Female, $\mathrm{n}(\%)$ & Total, $\mathrm{n}(\%)$ \\
\hline $17-20$ & 0 & 1 & 1 \\
$21-30$ & 1 & 0 & $4(57.1)$ \\
$31-40$ & 3 & 0 & 1 \\
$41-50$ & 1 & $2(28.6)$ & $7(100)$ \\
\hline
\end{tabular}

Table 2. Demographic and clinical features.

\begin{tabular}{|c|c|c|c|c|c|c|c|c|c|c|c|c|c|}
\hline ID & $\begin{array}{l}\text { Gender, } \\
\text { age }\end{array}$ & Swelling* & $\begin{array}{l}\text { Fountain } \\
\text { Sign }^{\#}\end{array}$ & Side & $\begin{array}{c}\text { Past history } \\
\text { of incisional } \\
\text { biopsy }\end{array}$ & $\begin{array}{c}\mathrm{Cx} \\
\mathrm{LN}^{@}\end{array}$ & $\mathrm{HT}^{!}$ & Workup & $\begin{array}{l}\text { Size of } \\
\text { CBT }\end{array}$ & $\begin{array}{l}\text { Shamblin } \\
\text { Class }\end{array}$ & $\begin{array}{l}\text { Resection } \\
\text { with preserved } \\
\text { ICA }\end{array}$ & $\begin{array}{l}\text { ECA } \\
\text { ligation }\end{array}$ & $\begin{array}{l}\text { Postop. } \\
\text { ND }^{\wedge}\end{array}$ \\
\hline 1 & M, 24 &,$+ 4 \mathrm{yr}$ & + & $\mathrm{R}$ & - & + & - & $\begin{array}{c}\text { US, CT, } \\
\text { conventional } \\
\text { arteriography }\end{array}$ & $5 \times 3 \mathrm{~cm}$ & I & + & - & Nil \\
\hline 2 & M, 46 &,$+ 25 \mathrm{yr}$ & + & $\mathrm{R}$ & - & - & - & $\begin{array}{c}\text { US, CT } \\
\text { angiography }\end{array}$ & $3 \times 3 \mathrm{~cm}$ & I & + & - & Nil \\
\hline 3 & $\mathrm{~F}, 17$ &,$+ 3 \mathrm{yr}$ & + & $\mathrm{L}$ & - & - & - & $\begin{array}{c}\text { US, CT } \\
\text { angiography }\end{array}$ & $3 \times 3 \mathrm{~cm}$ & II & + & - & Nil \\
\hline 4 & F, 35 &,$+ 1 \mathrm{yr}$ & + & $\mathrm{R}$ & - & - & - & US, CT & ? & II & + & - & $\mathrm{XII} \mathrm{n}^{\$}$ \\
\hline 5 & M, 37 &,$+ 2 \mathrm{yr}$ & + & $\mathrm{L}$ & - & - & - & $\begin{array}{c}\text { US, CT } \\
\text { angiography }\end{array}$ & $5 \times 3 \mathrm{~cm}$ & II & + & - & Nil \\
\hline 6 & M, 31 &,$+ 10 \mathrm{yr}$ & + & $\mathrm{L}$ & + & - & - & $\begin{array}{c}\text { US, CT, } \\
\text { Conventional } \\
\text { angiography }\end{array}$ & $6.2 \times 5.3 \mathrm{~cm}$ & III & + & + & Nil \\
\hline 7 & $\mathrm{M}, 40$ & + , ? & + & $\mathrm{R}$ & - & - & + & US, CT & $6.4 \times 3.2 \mathrm{~cm}$ & II & + & + & Nil \\
\hline
\end{tabular}

*Slowly growing painless pulsatile swelling below the angle of the mandible for some duration; *A swelling moveable horizontally but not vertically; ${ }^{\circledR}$ Cervical lymphadenopathy; 'Hypertension; ${ }^{\wedge}$ Postoperative neurological deficits; ${ }^{\$}$ Ipsilateral tongue deviation. 


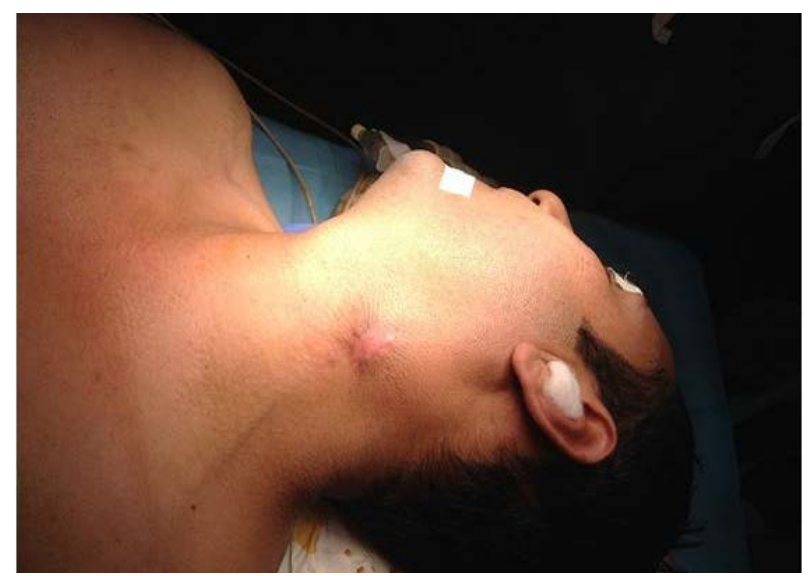

Figure 3. An old scar of previous incisional biopsy.

Table 3. Influence of shamblin tumour class on early neurological deficits (ENDs).

\begin{tabular}{cccc}
\hline Shamblin class & Patients $\mathrm{n}$ & ENDs $\mathrm{n}$ & P value \\
\hline I and II & 6 & 0 & The result is significant at $\mathrm{p}<0.05$ \\
III & 1 & 1 & 1 \\
Total & 7 & & \\
\hline
\end{tabular}

Details of workup are shown in Table 4. The characteristic finding of CBT on US examination is a hypervascular mass at carotid bifurcation with splaying of carotid arteries whereas the conventional and CT angiography usually revealed a tumour blush, splaying of carotid arteries and the feeding vessels of the tumours.

\section{Discussion}

Head and neck paragangliomas are rare neoplasms comprising about $0.03 \%$ of all human tumors. The annual incidence is around $0.001 \%$ [4]. This study involved 7 patients over a 4-year period (1.75 patients per year). Our first series [7] involved 8 patients in 12 years (0.66 patients per year). (There is a significant rise in hospitalbased incidence of CBTs in Iraq since 2008 p < 0.05). Comparing our incidence to others (Table 5); we'll see that the Mayo Clinic has reported the largest series to-date, describing 153 cases over a period of 50 years (around 3 patients per year) [14]. Most other studies (apart from the Iranian study) reported lower hospital-based incidences of CBT (0.7 - 1.3 patient per year). Thus the number of CBTs described in our study is good. The high incidence reported by Salehian et al. from Iran is firstly due to inclusion of pathological lesions other than carotid paragangliomas such as schwannoma and mesenchymoma (when excluded, the incidence would fall to 5.3 patients per year) and secondly due to the high altitude of Tehran (1200 meter above the sea level) which may be an etiological factor for CBTs [7] [8].

The peak age of the patients was in the $4^{\text {th }}$ decade. This finding is similar to other reports "Most patients become symptomatic between their $30^{\text {th }}$ and $60^{\text {th }}$ birthday” [4] [5].

In this study, male to female ratio was 2.5:1. However, other studies state that females are more frequently involved [1] [8] [16]. Rodriguez-Cuevas et al. and Luna-Ortiz et al. [cited in 6] declare that male and female distribution is equal except at high altitude where females appear to predominate [6].

\subsection{Clinical Features}

The results of this study coincide with the published literature about the most frequent symptom of CBT that is a slowly growing painless mass below the angle of the mandible discovered by the patient or an examiner incidentally [1] [7] [12] [17] associated with positive Fontaine sign (a swelling that is moveable horizontally but not vertically due to adherence to carotid bifurcation) [1] [4]-[6] [14] [15] [17]. Most HNPs usually exhibit an indolent growth pattern with a median increase in size of $0.83 \mathrm{~mm} / \mathrm{year}$ [9]. 
Table 4. Workup of patients.

\begin{tabular}{|c|c|c|}
\hline Technique & Patients, n (\%) & Comments \\
\hline US and Doppler neck exam & $7(100)$ & $\begin{array}{l}\text { It was accurate in ( } \mathrm{n}=6,85.7 \% \text { ) of cases. } \\
\text { One case of CBT was falsely diagnosed } \\
\text { as an enlarged lymph node. }\end{array}$ \\
\hline $\begin{array}{l}\text { CT scan of the neck with } \\
\text { iv contrast (Figure } 4 \text { ) }\end{array}$ & $2(28.6)$ & $\begin{array}{l}\text { It provided more detailed description of the } \\
\text { tumour extent, encasement of carotid } \\
\text { arteries and local invasion. }\end{array}$ \\
\hline MRI of the neck & $0(0)$ & $\begin{array}{l}\text { It was the least used imaging method } \\
\text { despite its well-known advantages. }\end{array}$ \\
\hline Carotid arteriography & $5(71.4)$ & \\
\hline Conventional angiography & $3(42.6)$ & $\begin{array}{l}\text { It used to be the gold standard test for CBT. } \\
\text { It has merits and demerits. }\end{array}$ \\
\hline CT angiography (Figure 5) & $2(28.6)$ & \\
\hline FNAC & $0(0)$ & \\
\hline Incisional biopsy & 1 (14.3) & It was risky. \\
\hline $\begin{array}{l}\text { Serum or urinary } \\
\text { catecholamine assay }\end{array}$ & $0(0)$ & $\begin{array}{l}\text { It was not done, although it was indicated } \\
\text { particularly in the hypertensive patient. }\end{array}$ \\
\hline Routine blood tests & $7(100)$ & $\begin{array}{l}\text { CBC, FBS, BU, S. Creatinine, bleeding and } \\
\text { clotting times, and virology studies. }\end{array}$ \\
\hline
\end{tabular}

Table 5. Incidence of CBTs in different studies.

\begin{tabular}{cc} 
Mayo Clinic, USA [14] & 153 cases/50 yr: 3.06 \\
Hussen W. M., Iraq [7] & 8 cases/12 yr: 0.66 \\
Salehian et al., Iran [8] & 97 cases/16 yr: 6.06 \\
O’Neill et al., Ireland [6] & 29 cases/22 yr: 1.3 \\
Wang et al., USA [5] & 29 cases/25 yr: 1.2 \\
Tayyab et al., Pakistan [14] & 8 cases/11 yr: 0.7 \\
Patetsios et al., USA [15] & 29 cases/30 yr: 0.97 \\
The present study, Iraq & 7 cases/4 yr: 1.75 \\
\hline
\end{tabular}

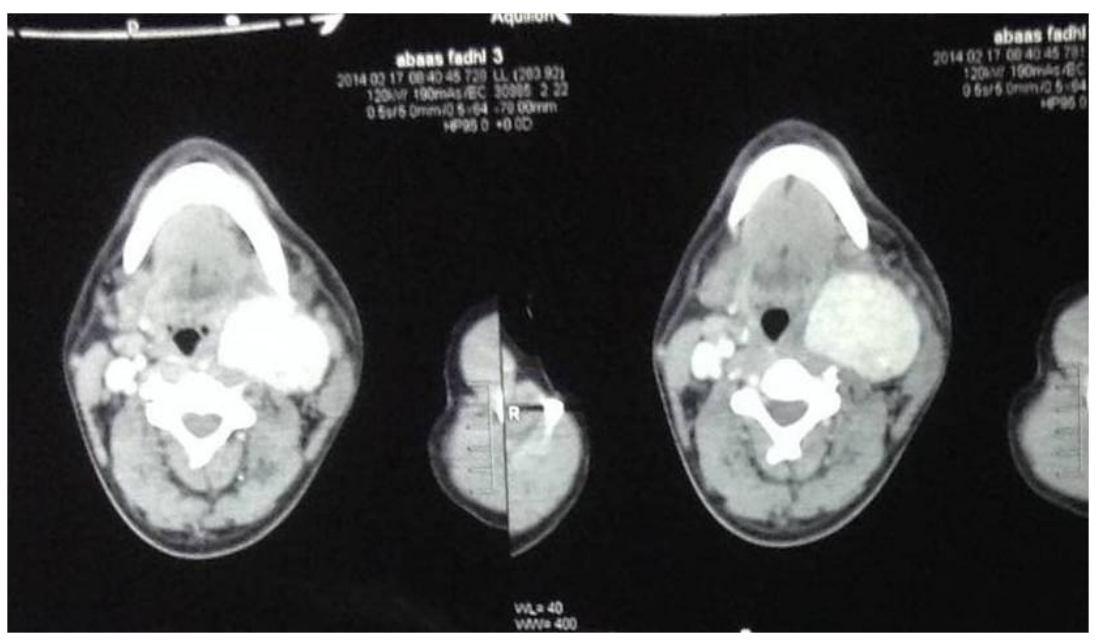

Figure 4. Contrast-enhanced CT scan showing left BCT in one of our patients. 


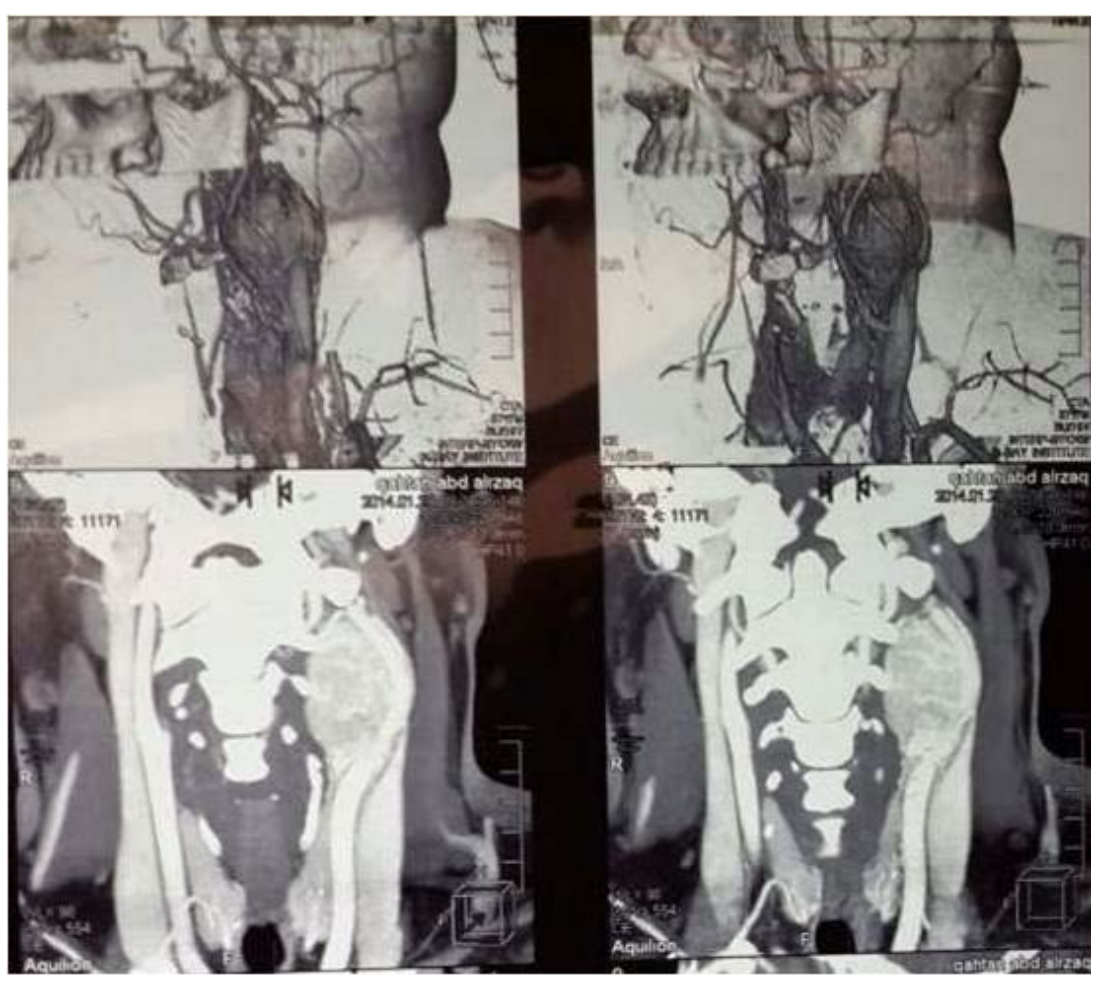

Figure 5. CT angiography in one of our patients with left CBT. All figures are from Prof. Waleed MH. MBChB, MS., FIBMS. FACS. MRCS, FRCS.

The swelling may be very small producing just neck asymmetry or very huge. The presence of a bruit over the mass is uncommonly noted but when present suggests significant compression of the artery [1] [5] [15] and strengthens a tentative diagnosis of CBT [4]. As the carotid bifurcation lies close to many cranial nerves, expansion of the tumour may lead to cranial nerve paresis (VII, IX, X, XI and XII) resulting in symptoms of dysphagia, choking or hoarseness [1] [4] [15]. Tumour extension to the skull base has been seen in advanced cases [17] and Horner's syndrome has been reported as a rare complication [4] [15] [17].

All patients in this series exhibited a unilateral neck swelling of variable sizes with positive Fontaine sign but none had a neurological deficit preoperatively. Most of the sporadic CBTs (95\%) are unilateral [5].

One patient was hypertensive complaining of headache (14.3\%). Unfortunately, he was not investigated by serum or urinary catecholamine measurement to exclude a functioning CBT. Well, studies mention that functional CBTs can cause paroxysmal hypertension which should disappear after surgical resection of the tumour; otherwise, if hypertension persists following surgery, then it might be due to other causes [5] [14] [15].

\subsection{Diagnosis}

When a carotid body tumor is suspected, an imaging study is the next diagnostic step. Bilateral carotid angiography is the most sensitive imaging technique [5]. This technique (once considered the gold standard) has its merits and demerits.

"Vascular mass displacing the internal and external carotid arteries at the bifurcation is essentially diagnostic of a carotid paraganglioma [8]. Paraganglioma is a highly vascularized tumor displaying a specific pattern in angiography; compact vascular network (tumor blush) with a distinct border usually derived from the external carotid artery is seen. It is located at the bifurcation of the carotid artery and due to the size of the tumor these two branches are separated from each other. In the larger tumors, these arteries pass through the bulk of the tumor" [8]. Five patients (71.4\%) in this series underwent carotid arteriography whereas it was done to all patients in Hussen study [7]. It was also the mainstay of final diagnosis of all patients in the study of Tayyab et al. from Pakistan [14]. In contrast, it was used in 11/29 patients in the Irish study [6], in which conventional angiography has been replaced by US as a first-line diagnostic modality [6]. 
In the current case series, all patients had US examination of the neck together with colour Doppler imaging which was very useful. "On sonography, paraganglioma present as a well-defined, solid hypoechoic mass and on color Doppler imaging, hypervascularity with a low-resistance flow pattern is seen” [4] [8]. Most recent studies report using sonography and colour Doppler imaging as first-line diagnostic modality for CBT [6]-[8]; due to its simplicity, non-invasiveness and high accuracy although it is operator-dependent.

Noninvasive imaging studies such as CT, MRI, and magnetic resonance angiography are also excellent methods for evaluation [5]. They are especially useful in determining the extent of the tumour [8]. In our study, 2 patients (28.6\%) had had contrast-enhanced CT scan of the neck which really provided a detailed description of the tumour and its extent. MRI was not used despite its known advantages probably because the patients had already a CT scan.

An open biopsy should not be attempted when a carotid body tumor is suspected because of the highly vascular nature of these tumors, and it is generally not necessary for diagnosis [5]. However, one patient (14.3\%) in this study was subjected to fruitless attempt of surgical removal or incisional biopsy being suspected as enlarged cervical lymph nodes.

The head and neck surgeon should have a high index of suspicion when facing a unilateral neck swelling in the region of carotid bifurcation. Carotid paraganglioma should be the top differential diagnosis in such a situation [5] [7] [8] [14] [15]. Confirmatory workup should come next followed by proper pre-operative preparation to avoid surgical complications.

\subsection{Treatment}

Controversy is faced everywhere in the literature related to CBT. Treatment options are just an example of this varied opinion. On one hand, surgery is considered by many authors as the standard therapy as it provides an immediate and complete removal of the tumour [1] [7]-[9]. However, the morbidity of cranial nerve injuries and stroke associated with surgery is significant [1] [7]-[10] [17]. On the other hand, the indolent and very slow growth rate of CBT and the fact that most of them are benign and rarely cause death by themselves encourage some authors to adapt the conservative or the so-called (wait and scan) policy [9]. A third group of workers recommend radiotherapy as a primary mode of management of CBTs to achieve a tumour growth control while avoiding the potential morbidity of surgical intervention [9].

In our series, all patients were managed surgically because all were symptomatic and have accepted the explained risks of surgery.

\subsection{Preoperative Embolization}

The routine use of preoperative embolization is controversial because of the potential neurologic complication associated with the accidental reflux of particulate matter into the ophthalmic or cerebral circulation. Some authors advocate its use before the resection of large tumours because it may decrease the vascularity of the tumour, reducing intraoperative blood loss and transfusion requirements. The apparent benefit of embolization should be weighed against the risk of stroke [1]. Its current use is limited to tumours greater than $5 \mathrm{~cm}$ in diameter [1].

In our study, this technique hasn't been used simply because we do not have the necessary expertise in this technique. Kafie et al. (2001) from USA published a nice report of 2 patients with CBTs greater than 4 cm successfully embolized with gel the day before surgery; an intervention that made resection smoother, safer and with minimum blood loss [10].

\subsection{Surgery}

We utilized the technique of sub-adventitial dissection for tumour excision in our cases that is adapted by many authors [1] [5] [9] [15] to minimize the blood loss. However, some authors prefer dissection in the capsular-adventitial plane [1] [17] [18] while others use the cranio-caudal dissection introduced by van der Bogt [cited in 9] to reduce the risk of cranial nerve and carotid artery damage. Shibuyaa et al. thinks that the classical operation described by Gordon-Taylor of sub-adventitial dissection carries a risk of arterial wall injury and prefers dissection in the capsular-adventitial plane [17].

The ECA was ligated in 2 of our cases as it was densely involved by the tumour. This is considered by many 
authors an important maneuver to minimize the blood loss during resection of CBTS which receive their blood supply from this artery [9].

Ferreira et al. (2013) from Portugal reported 4 cases of CBTs resected using an ultrasound dissector [19]. They believe that this technique improves the safety of excision, decrease the technical difficulties, lower blood loss and shortens the operation time [19].

Carotid BTs grow in a longitudinal direction and hence tend to involve the cranial nerves in proximity to them [9]. Therefore, the vagus and hypoglossal nerves in this series were isolated at the initial stage of the operation to avoid their injury.

Modified intra-luminal carotid shunts were prepared in some of our cases but were not used. The use of such shunts during resection of CBTs is controversial. Patetsios et al. believe that familiarity with the use of intraluminal vascular shunts is critical since the vessel wall is easily damaged during sub-adventitial dissection [15]. In his institute (Baylor University Medical Center) a temporary in-lying carotid shunt is used routinely whenever vascular reconstruction is required [15]. Moreover, for large tumours, a shunt may be placed through a common carotid arteriotomy before tumour dissection begins to decrease bleeding and prevent an interruption of cerebral blood flow in the event of vessel injury [15]. Previously they used to utilize temporary shunting only when carotid stump back pressure is $<50 \mathrm{mmHg}$ [15].

In our series, the tumours were classified according to Shamblin and the intra-operative findings into 3 groups. Suarez et al. states that Shamblin classification is the most widely used staging system for CBTs [9]. However, it is not a tool of prognostic value but it does allow us to compare the outcomes of surgically favorable, intermediate and challenging cases (classes I-III) [9].

For the sake of better understanding the outcome of surgery we divided our patients into 2 subgroups:

1) Resection of CBT with preservation of carotid arteries $(n=5)$.

Suarez et al. in a retrospective review of 2175 CBT resections reported 483 (22\%) cases of new cranial nerve permanent deficits [9]. In our study, the overall persistent cranial nerve deficits were 1/7 (14.3\%) that is within the international standard.

2) Resection of CBT with ligation of ECA only $(n=2)$. In both cases, the tumours were benign class II and III with encasement of carotid bifurcation. The ECA was ligated as it was heavily involved by the tumours. The outcome was uneventful. Safety of ligation of ECA is widely addressed in the literature [20]. Shibuyaa et al. recommends ligation of the ECA before tumour dissection if it is the feeding vessel of the tumour, in order to make it easy to detach the capsule from the adventitia and to control the bleeding safely [17].

\subsection{Influence of Shamblin Tumour Class on the Rate of Postoperative Neurological Damage}

This study clearly shows that Shamblin class III significantly influenced the occurrence of early neurological deficits $(\mathrm{p}<0.05)$. According to Makeieff et al., the rate of serious complications, i.e., permanent nerve palsy, and vascular complications was $2.3 \%$ for Shamblin Class I/II tumors and $35.7 \%$ for Shamblin Class III tumors ( $<$ 0.001) [9] and O'Neill et al. found in his series that cranial nerve injury was more likely following the removal of larger tumours [6].

\section{Conclusion}

Our study revealed a noticeable increase in the hospital-based incidence of CBT in Iraq since 2008. The diagnosis of CBT can be made easily if a high index of suspicion is coupled with the necessary investigations. Our results of surgery for CBT compare very well with the international standards.

\section{Acknowledgements}

We would like to thank Dr. Sabah N Jaber FIBMS (CTVS) for his permission to report his patient (the $4^{\text {th }}$ in this series).

\section{Conflict of Interest}

None is declared. 


\section{Authors' Contribution}

A: Study design, B: Data collection, C: Statistical analysis, D: Data interpretation, E: Manuscript preparation, F: Literature search. Waleed M. Hussen: A, B/Abdulsalam Y. Taha: A, B, C, D, E, F/Diar S. Hama-Kareem: A, B.

\section{References}

[1] Gupta, B. and Mitra, J.K. (2007) Anaesthetic Management of Chemodectoma Excision. The Indian Anesthetists, Forum. www.theiaforum.org

[2] Wikipedia, The Free Encyclopedia (2014) Carotid Body. Internet Monograph. http://en.wikipedia.org/wiki/Carotid_body

[3] (1983) The Human Carotid Body. Thorax, 38, 561-564. http://dx.doi.org/10.1136/thx.38.8.561

[4] Boedeker, C.C. (2011) Paragangliomas and Paraganglioma Syndromes. GMS Current Topics in Otorhinolaryngology—Head and Neck Surgery. http://www.egms.de/static/en/journals/cto/2012-10/cto000076.shtml

[5] Wang, S.J., Wang, M.B., Barauskas, T.M. and Calcaterra, T.C. (2000) Surgical Management of Carotid Body Tumors. Otolaryngology-Head and Neck Surgery, 123, 202-206. http://dx.doi.org/10.1067/mhn.2000.106709

[6] O’Neill, S., O’Donnell, M., Harkin, D., Loughrey, M., Lee, B. and Blair, P. (2011) A 22-Year Northern Irish Experience of Carotid Body Tumours. Ulster Medical Journal, 80, 133-140.

[7] Hussen, W.M. (2008) Carotid Body Tumour. Journal of Faculty of Medicine Baghdad, 50, 410-413.

[8] Salehian, M.T., Ghoddoosi, I., Marashi, A. and Fazel, I. (2002) Carotid Body Tumours: Survey of 97 Patients. Archives of Iranian Medicine, 5, 1-5.

[9] Suarez, C., Rodrigo, J.P., Mendenhall, W.M., Hamoir, M., Silver, C.E., Grégoire, V., Strojan, P, Neumann, H.P., Obholzer, R., Offergeld, C., Langendijk, J.A., Rinaldo, A. and Ferlito, A. (2013) Carotid Body Paragangliomas: A Systematic Study on Management with Surgery and Radiotherapy. European Archives of Oto-Rhino-Laryngology, 271, 23-34. http://link.springer.com/article/10.1007/s00405-013-2384-5

[10] Kafie, F.E. and Freischlag, J.A. (2001) Carotid Body Tumours: The Role of Preoperative Embolization. Annals of Vascular Surgery, 15, 237-242. http://dx.doi.org/10.1007/s100160010058

[11] Taha, A.Y. and Hama-Kareem, D.S. (2014) Surgery for Carotid Body Tumours. Ph.D. Thesis, Iraqi Board for Medical Specializations, Baghdad.

[12] Al-Ward, M.M. (Producer) (2010) Left Carotid Body Tumour (Video); 1:13 Minute. http://www.youtube.com/watch?v=Ui6VOdtX_qk\&feature=autoshare

[13] Abdulrahman, H. (Producer) (2013) Carotid Body Tumour (Video); 5:34 Minute. http://www.youtube.com/watch?v=2fgahD $7 \mathrm{rmQ}$

[14] Tayyab, M., Khan, M.R. and Sophie, Z. (2003) Presentation and Management of Carotid Body Tumors. JPMA, 53. http://www.jpma.org.pk/full_article_text.php?article_id=227

[15] Patetsios, P., Gable, D.R., Garrett, W.V., Lamont, J.P., Kuhn, J.A., Shutze, W.P., et al. (2002) Management of Carotid Body Paragangliomas and Review of a 30-Year Experience. Annals of Vascular Surgery, 16, 331-338. http://dx.doi.org/10.1007/s10016-001-0106-8

[16] Buckingham, E. and Ryan, M. (2002) Paragangliomas (Unpublished Lecture Notes). Department of Otolaryngology, The University of Texas Medical Branch, Galveston.

[17] Shibuyaa, Y., Umedab, M., Yoshikawab, T. and Komori, T. (2002) Carotid Body Tumour: Case Report. Oral Oncology, 38, 313-317. http://dx.doi.org/10.1016/S1368-8375(01)00057-4

[18] Wieneke, J.A. and Smith, A. (2009) Paraganglioma: Carotid Body Tumor. Head and Neck Pathology, 3, 303-306. http://dx.doi.org/10.1007/s12105-009-0130-5

[19] Ferreira, J., Canedo, A., Braga, S., Vasconcelos, J., Gouveia, R., Martins, V., Brandão, P. and Vaz, A. (2013) Carotid Body Tumours Resection with Ultrasound Dissector. Chinese Medical Journal, 126, 586-588.

[20] Taha, A.Y. (2013) Penetrating Carotid Artery Injuries. The Iraqi Postgraduate Medical Journal, 12, 96-103. 